The International Journal Of Engineering And Science (IJES)

|| Volume || 6 || Issue || 1 || Pages || PP 56-60 || 2017 ||

ISSN (e): 2319 - 1813 ISSN (p): $2319-1805$

THE IJES

\title{
Reason for the Vogue of Chinese Stories of Talented Scholars and Beauties and Its Effect to the Japanese, Korean and Vietnamese Literature
}

\author{
Guo Jian Xun, Pham Quynh Son \\ College of Chinese language and literature, Hunan University, China
}

\begin{abstract}
-
Chinese stories of talented scholars and beauties appeared at the end of Ming Dynasty and had a great vogue in the early of Qing Dynasty. This type novel as its name implies, tells about a challenging love story between a "scholar" and a "beauty". Although it neither contains high art degree nor greatly affect overall indigenous literature, it became prevalent in some periods, even spread its fame to some neighboring countries such as Vietnam, Japan and Korea. This article will offer a number of explanations for why stories of talented scholars and beauties was not highly appreciated but could flourish in Chinese society and its influence to the literature of Vietnam, Japan, Korea.
\end{abstract}

Keyword: Chinese stories of talented scholars and beauties, Vietnamese Nom story, Japanese novel, Korean novel, effect.

Date of Submission: 15 November 2016

Date of Accepted: 15 January 2017

What is "stories of talented scholars and beauties"? "A brief history of the Qing Dynasty novel" defined as follows: "stories of talented scholars and beauties" refers to a kind of episodic novel about the love story of young men and women that first appeared at the end of the Ming and had great vogue in the early of Qing. It is another kind of love novels. It contains about 10 to 24 chapters, mostly 16 chapters with no more than 200 thousand words. In terms of its content and topic, this type of novel described a love and marriage story between a talented student and a beautiful girl who was original in a rich family. It was divided into three parts: (1) Men and women had the love at first sight, (2) They were separated by a bad guy; (3) The talented student passed the exam and had the reunion with his love."

According to statistics, from the late Ming and early Qing Dynasty, the most popular works in the Chinese society include : "Hao Qiu Zhuan", "Yuan Ru Yue", "Yu Jiao Li”, "Ping Shan Leng Yan”, "Ding Qing Ren", "Bai Gui Zhi”, "Yuan Yang Mei”, "Hua Tu Yuan”, "Wu Jiang Xue”, "Yu Zhi Ji zhuan”, "Ren Jian Le”, "Nü Kai Ke", "Jin Xiang Ting”, "Xing Feng Liu”, "Feng Huang Chi”, “Chun Liu Ying”, "He Pu Zhou”, "Yin Feng Xiao", "Yu Lou Chun”, "Sheng Hua Meng”, "Xi Hu Xiao Li”, “Zhu Chun Yuan Xiao Li”, "Kuai Xin Bian”, "Huan Zhong Zhen”, "Meng Zhong Yuan", "Mo Lan Jia Hua”, "Qi Lin Er Zi Bao", "Xiu Ping Yuan”, "Gu Shan Zai Meng”, “Qiao Lian Zhou”, “Jin Yun Qiao Zhuan”, “Zai Hua Ling”, “Wu Feng Yin”, “Fei Hua Yan Xiang”, "Wu Mei Yuan".

\section{REASON FOR THE VOGUE OF CHINESE STORIES OF TALENTED SCHOLARS AND BEAUTIES}

Chinese stories of talented scholars and beauties appeared in the end of Ming Dynasty and grew strongly in the interval of Ming and Qing dynasties that created professional writers and printings as well as the literature places to consume the novels. This kind of novel monopolized most of the novel market and became popular in the society for the first 30-40 years of Qing. However, it was not highly appreciated by critics by its normal art level and patternization.

Stories of talented scholars and beauties, one of the Chinese literature genres, aren't really appriciated by literacy critics because of its average level of art as well as its main motif of literature writing being "thousand people with one face and all the novels with one tone". Especially, according to famous Chinese writer Cao Xue Qin, he bitterly criticized this genre of literature: "As for love novels, thousand books has only one literature tone which can't help mentioning to lust. Every single page is flooded with such names as Pan An, Zi Jian, Xi $\mathrm{Zi}$, Wen Jun. It is only because the author wants to write some love poetry by himself, he fictionalizes names of men and women together with small-minded guys interfering in their relationships as clow characters in dramas". 
In the Chinese history, the authorities, moreover, used to consider novels superstitious cultural products. Therefore, they used their political power to inhibit and ban this literature genre, especially in the Qing Dynasty. From Shunzhi to Daoguang period, every emperor in their enthronement all "put ban on novels consisting of lewd words". On April of the $53^{\text {rd }}$ year under Shunzhi period, Kangxi Emperor stipulated that "those publishing novels with lewd words will be dismissed if they are officials, beaten 100 times with a rod and exiled 300 miles if they are soldiers or cilivians. Those trading such novel type will be beaten 100 times and exiled in 3 years." (extracted from "Kang Xi Shi Lu"). Orthodox writers regarded novels as products in need of elimination. They even used the most terrifying words to curse such novel's authors, especially in the Qing Dynasty. As for Liang Gong Chen, "Because Shi Nai An clearly described the nefarious activitites in his novel "In the Water Margin" as drawing, his 3-generation descendants are all dumb. Because Jing Sheng Tan gave comments on the book "Xi Xiang Ji" and many other books, he was sentenced to death without an heir." (Liang Gong Chen, "Quan Jie Lu Si").

Obviously, the social enviroment for the novel's development is extremely harsh. Hence, there arises a question: Why did the novels without high-level art bewteen the late Ming and early Qing Dynasties achieve prosperity? The explanations can be given under different following aspects.

\section{Descriptive pattern of Stories of talented scholars and beauties is inheritance of long-standing literature pattern.}

Descriptive pattern of Stories of talented scholars and beauties has a long-standing history. It was first seen in "Shi Jing" - the very first Chinese poem collection. In the first chapter "Guan Jiu", to describe the love of man and woman, the author wrote "The modest, retiring, virtuous, young lady; For our prince a good mate she", then "He sought her and found her not; And walking and sleeping he thought about her" and "Where are you, my love" in "Jian Jia". It was a transformation of feelings, from the joyment of reunion, desire for remembrance to the sadness of separation. Legend of Tang Dynasty also has a number of same patterns, such as "Liu Yi", "Ying Ying", "Cui Xiao Yu". Those charming love stories have been being handed down with beautiful words until now.

"Xi Xiang Ji" - the antecedent of the "Stories of talented scholars and beauties' line, along with innumerable adaptations, namely "Ping Shan Leng Yan", "Yu Jiao Li", "Hao Qiu Zhuan" have become typical works of this type. Stories of talented scholars and beauties in the beginning of Qing Dynasty had developed to be a major literary line. Plot of this line basically followed this pattern: a gentleman accidentally met a stunning girl in his journey, then they fell in love with each other at first sight. Unfortunately, due to strict feudal rites, the two were not reachable. Thanks to her maid for being her postman, they could write for each other and get engaged in secret. Then a bad man appearred and separated them, the girl was forced to get married to another man. Speaking of the girl's fiance, he then made every effort to study and reserved for the best scholar. Thanks to the King, the two were eventually reunited.

\section{Writers find Stories of talented scholars and beauties as therapy for themselves}

In ancient China, the only way for a man to build up his career is to study, get high rank in exams and become a mandarin. A man's will is to train himself, final goal of education is to become a mandarin. Imperial examinations appeared in Sui Dynasty and Tang Dynasty saw it as the only way for men to develop their career. The examination system in the Song Dynasty had been reformed and perfected to high levels. The exam was hold annually and the number of candidate also went up dramatically. In the $3^{\text {rd }}$ year of Tai Zong Chun Hua, the total amount had increased to over 13,000. To the end of North Song Dynasty, the number of doctor in one exam only had reached 800, many times larger than the total number over 29 years of Tang Kai Yuan time. In Ming Qing time, mandarins were selected by means of empirical examination (Ming shilu). Since then, the exam had become an important step that ancient writers chose to realize their own value. Once they got high rank in the exam, they would become very important person and help to bring fame to their family. That was the biggest honor of a person. It can change people's life over a night. People often said that, "Ages of studying are seen by no one, moment of being eligible is widely known". The situation of Fan Jin in "Ru Lin Wai Shi" before and after he passed the exam can be taken as an example. Xue Yuan Chao of Tang Gao Zong Dynasty also exclaimed that: "There were 3 things that I regretted for not being able to do: be a doctor, get married to a girl from one of five families (Wang, Lu, Zheng, Li, Cui) and compose national history”. Even Xue Yuan Chao who was under one but above all, also gave prominence to being a doctor can explain for the importance of this in the eyes of ancient scholars.

Beside career, what is also important for ancient scholars is marriage. They could never feel truly happy if their marriage was not up to their expectation, even if they were successful in their career. A perfect marriage to a majority of writers means weddings to girls from wealthy families. In ancient concept, getting high rank in exam and marrying a highborn girl are the most burning desire of any man. Researchers had shown that in feudal 
society, "marriage is a political act, an opportunity for families to link together to promote the power of them. Once those scholars got favor to be sons-in-law of wealthy families, they could get special privilege to go further on their career.

In fact, getting high rank in exam was only the beginning step on their career, but it also was their foundation to a perfect marriage life, and the later, on the contrary, had huge impacts on their career as well as financial status. It could be assumed that the two had mutual influence and they were used as criteria to evaluate their living standard. However, the special historical situation of the late Ming and early Qing time had ruined their living idea. It was the time of chaotic and unorganized society. It was the transition between two dynasties when many scholars had to suffer from war without nothing to depend on.

In the Qing dynasty, the Man potentate aimed to implicate and win the hearts of Han, especially the Han intelligentsia. Although the exam system was gradually restored, the possibility of taking exam decreased dramatically. In Shun Zhi's third year, even though the exam system was restored in some local areas, the quota was very limited when the eligible people were mainly royal members. Moreover, the Man governor still suspected the Han and kept mobilizing the so-called "Literal prison" (pleading one's literature to put himself in jail) to push cynicism. Together with the current corrupted exam system, the talented people were always illtreated, which led to the fact that the majority of scholars couldn't become mandarins or even lived unsafely due to lurking catastrophe. As a result, the fantasy of "getting married with a girl born in a rich family" would never become real.

During that harsh social context, the scholars found the pens and papers to express all of their innate agony, seek solace and release themselves spiritually. One of those was the novels of "talent and beauty" which could be obviously understood by two ways: one is creating and the other is reading that kind of novels. Right because of that special era with those things encountered, the majority of lower-class scholars had the concept of "filling a vacancy" whose production was "talent and beauty" novels.

Under the dominance of the aforementioned concept, the typical scholars of lower class such as Tian Hua Cang Zhu Ren and Yan Shui San Ren borrowed "talent and beauty" novels to imply the ideology of human life incessantly nurtured but never became real. The "talent" in this kind of novel was good-looking men holding many talents, taking exam successfully and being faithful. They finally became mandarins, were highly appreciated by the Court and got married to the woman they loved. Meanwhile, the "beauty" was beautiful ladies with poetical literacy and faithful love who dared to resist feudalism to seek a happy life with their "talents". Besides inventing stories, there were many other scholars of lower class read "talent and beauty" novels as a way to seek solace and release themselves spiritually. They wallowed in the stories of ideal love and marriage to escape from the tough reality as what they desired lied all there. This reading concept motivated and boosted this kind of novels to be prolifically created, leading to its prosperity.

\section{Traders utilize Stories of talented scholars and beauties as an effective money-making tool}

In the late Ming Dynasty, capitalism began to emerge in the Chinese society. Commodity economy and the people's commodity economy awareness compared to the previous periods witnessed an unprecedented development. Given the enormous business development, the social economy was considerably promoted; however, everything has its dark side. While the trader class's status enjoyed an incredible surge, writers' status went through a catastrophic lapse. Society gradually lost their respect for the intellectual but worshiped the power of money. As in "Jin Ping Mei" publication, widow Meng Yu Lou refused to marry Shang bachelor because he was just a poor intellectual man, yet delighted to accept the position of wealthy Ximen Qing's concubine in spite of his reputation as a womanizer. Also, money could even purchase an illiterate person a high-positioned job. Ladies were considered as goods to be exchanged from this man to another, as long as there was money. Qiao in "Jin Yun Qiao" story is a typical example of such tragedy for woman in feudal society. Hence, the seriously negative impacts of money on residents could be clearly seen. In such a social context, book sellers - running after the profit - treated novel as other normal commodities and mainly offered the ones obtaining large consumption quantity no matter how the novel's quality was.

Although Stories of talented scholars and beauties was not of high-art level, but as mentioned above, there were writers composing this kind of novel in order to find a sedative to ease the pain of failure in examinations, or there were people reading this type of writing to seek for the liberation of their souls. These could be the explanation for the popularity of Stories of talented scholars and beauties in the society. Book sellers saw that business opportunity. They, in order to link authors and readers, printed and offered widespread this kind of novel. Regarding the rapidly-consumed works such as "Ping Shan Leng Yan", "Yu Jiao Li", they published several editions. Also, these book sellers paid handsomely for the authors to attract more talented ones. Even in case of supply shortages, the book sellers would draft their own novels of gifted scholar and beautiful lady. Apparently, all of these book sellers' tricks aiming at their personal interests were key reasons for the development of novel of gifted scholar and beautiful lady. 


\section{Contemporary society desires Stories of talented scholars and beauties as a salvation for lost souls}

The late Ming Dynasty witnessed simultaneously the corruption of the feudal system and the infancy of capitalist economy, which all led to the consciousness awaken of people living in that society. On the other hand, due to the initiative of the radical thinkers like Li Zhi, protests appeared to suppress human's sexual desires. However, the objection was so strong that the existing extreme state was transitioned to the other extreme one; specifically from sexual prohibitions to unruly behaviors.

Since the mid-Ming Dynasty, there were talks and conversations about the "bedroom tactics". Many literary scholars showed unruly behaviors. In their publications, both Yuan Hong Dao and Yuan Zhong Dao frankly admitted being exhausted by being "Philogynist". Most people in contemporary society did not consider this as abnormal or strange; they even called themselves to be "affluent". Thus, a variety of erotic novels recommend people be unruly, lecherous was appeared, such as "Rou Pu Tuan", "Ru Yi Jun Zhuan", "Xiu Ta Ye Shi"...

However, everything must inevitably follow the laws of nature "zenith and implications". When the unruly reached an extreme point, it would create new hazards to society, like aesthetic traditions and customs lost, cultural degradation, moral decadence, value downward, or life-orientation lost. Specific literature illustration was the proliferation of erotic novels with full of lust factors. Despite of the prohibitions initiated by Court, the result was ineffective. Many literary scholars at that time realized that the people did not resist, or struggle against corruptive feudalism, but actually losing their own self-esteem. They started to think about the human values, and accordingly, drove the need for seeking a better guideline for life. Stories of talented scholars and beauties mainly described the lofty spiritual factors in marital love story between men and women; it could be the face, talent, temperament, feelings, and respect without any vulgar descriptions. All descriptions of marital love were full of stylish and elegant aesthetic which served as a reflection mirror, awakening people of how the actual society being degraded, how human's moral being seriously depraved. In all, it helped them to rediscover the value and true ideal of life.

What's more, the novel of gifted scholar and beautiful lady also revealed the corruption of feudal society, which was demonstrated through a power competition among the feudal groups, the exploitation of human autonomy, the money-exchange for positions and honors, or stealing people's possessions, even their wives, their lovers, and the lackey tried all tricks to destroy love of young couples just to satisfy their owners, etc. Because people were miserably suppressed and could not express emotions out, they felt extremely satisfied when the dark side of social reality being exposed in the books and included in the story. This somewhat freed their emotions which were normally unable to share with others.

Along with the economy development, in society appeared urbanite class which showed great interest in novels featured with full-of-obstacles love stories of gifted scholars. Consequently, Stories of talented scholars and beauties became more and more prevalent.

Therefore, it could be stated that the appearance of a large number of Stories of talented scholars and beauties was to respond the urgent demand and call of the society.

\section{INFLUENCES OF CHINESE STORIES OF TALENTED SCHOLARS AND BEAUTIES ON VIETNAMESE, JAPANESE AND KOREAN LITERATURE.}

Stories of talented scholars and beauties appeared not only in Chinese ancient literature but also in Vietnamese, Japanese and Korean literature. Apparently, content of those stories have been directly influenced by Chinese ones. However, there are a lot of differences in their writing style. For instant, Vietnamese Nom stories such as "Xi Xiang Ji”, "Er Du Mei”, "Yu Jiao Li", "Pan Chen Zhuan", "Bai Yuan Sun Ke", "Hua Jian Zhuan” borrowed the content of Chinese stories of talented scholars and beauties. Moreover, instead of using chapter fictions style, they use a unique writing style of Vietnam- Luc Bat poem (poems that always begin with a six-syllable line and end with an eight-syllable one).

One Chinese story may have impact on several stories in different countries. For example, "Ping Shan Leng Yan" was derived into a Luc Bat story with Nom character by Pham My Phu, a Vietnamese writer, and a ten book set by a Korean anonymous writer. "Jin Yun Qiao Zhuan", a story of a Chinese writer - Qing Xin Cai Ren, was the base for Nguyen Du to write Truyen Kieu, a masterpiece of Vietnamese literature, and for Japanese writer Kyokutei Bakin to write "Popular story of Kinjuro and Uoko". This work had also been rewritten into a Japanese work called "Popular story of Jin Qiao" by Nishida Korenori in 1973. This story was very popular in Japan and was adapted for Joruri and Kaburi stages.

Some Korean stories of talented scholars and beauties simulated the whole plot of Chinese original ones. The others just borrowed the main content of the origin. The most common plot is the love story between a noble man and a normal girl or a courtesan such as "Yeong Yeong tragedy", "Youth memories" or "The story of doctor Yi", etc.

The direct impact of Chinese stories of talented scholars and beauties on Vietnamese, Japanese and Korean works is through the common language (Han language), and ideology (Confucianism, Buddhism, Taoism). Confucians welcomed those stories first, and then were the normal people. As it was direct, the impact of 
Chinese stories of talented scholars and beauties was remarkable. Name of characters and places in Truyen Kieu were exactly the same as in the original work. Lee Mong-Ryong in "Chun Hyang Story" was a handsome and talented Korean man. He had the appearance of Du Mu Zhi (a Chinese poet of Tang Dynasty). He was as generous as the sea, and very intelligent. "His literature was as good as of Li Bai, his handwriting was as beautiful as of Wang Xi Zhi". Chun Huang, a beautiful girl of "Peaceful morning", had the appearance of Zhuang Jiang, morality of Ren, Si, talent of Tai Du, kindness of Tai Zi and loyalty of Er Fei”. All of them were Chinese standards. Due to the sentiment of "rewriting, not creating", writers preferred respecting the origin to creating their own stories.

Chinese works were the model. National factors, however, were also prominent. Works of each country were unique, and played their own role in literature development in their country. It is the interesting fact found while studying Chinese stories of talented scholars and beauties and the correlation among Chinese, Vietnamese, Japanese and Korean ones.

\section{REFERENCES}

[1]. Dang Thanh Le, Kieu story and the type of Nom story, Social Science Press, Hanoi, 1979.

[2]. A Ying, History of late Jing dynasty novels, Dong Fang Press, Beijing, 1996.

[3]. Lu Xun, A brief history of Chinese Literature, QiLu Press, Jinan, 1997.

[4]. Li Han Qiu, Hu Yi Min, Qing dynasty novels, AnHui Press, HeFei, 1997.

[5]. Lin Chen, A collection of stories of talented scholars and beauties, Liaoning Ancient Document Press, Shenyang, 1997.

[6]. Wu Cun Cun, Sexual trend in Ming Jing society, People's Literature Press, Beijing, 2000.

[7]. Wang Ru Mei, Zhang Yu, History of Chinese novel arguing, ZheJiang Ancient Document Press, HangZhou, 2001.

[8]. Ren Ming Hua, Studying stories of talented scholars and beauties, WenLian Press, Beijing, 2002.

[9]. Kieu Thu Hoach, Nom story: history of development and type of literature, Education Press, Hanoi, 2007.

[10]. Hou Jian Liang, Civil Mandarins of Ancient China, Party Building Publication Press, Beijing, 2010. 